\title{
Pathological study of genitourinary invasion by Aspergillus flavus in male rats
}

\author{
S.O. Kadhim ${ }^{1}$ and I.B. Faleh ${ }^{2} \odot$ \\ ${ }^{1}$ Department of Pathology and Forensic Medicine, College of Medicine, University of Misan, Misan, ${ }^{2}$ Department of Pathology \\ and Poultry Disease, College of Veterinary Medicine, University of Bagdad, Baghdad, Iraq
}

\begin{tabular}{l} 
Article information \\
\hline Article history: \\
Received September 20, 2021 \\
Accepted November 15, 2021 \\
Available online December 24, 2021 \\
\hline Keywords: \\
A. flavus \\
Genitourinary \\
Histopathology \\
Immunization \\
Mycotoxin \\
\hline
\end{tabular}

Correspondence:

S.O. Kadhim

sadsakumkum@gmail.com

\begin{abstract}
Due to the widespread of $A$. flavus spores and the high risk of its mycotoxins in our environment, we investigated the pathological effects of A. flavus on genitourinary system in experimental rats using a whole sonicated antigen (WSA), and modified mycotoxin (mycotoxoid) in the immunization process. Fifty albino male rats were involved, subdivided into five group, each group of 10 male rats. Group one as a negative control received phosphate buffer saline, group two as a positive control received a challenge dose of $1 \times 10^{6} / 0.5 \mathrm{ml}$ viable conidia/rat, while group three was immunized by a mixture of WSA and mycotoxoid, G4 was immunized by WSA alone, and G5 was immunized by mycotoxoid alone. The immunization was performed in two doses with 2 weeks interval. The results showed a high immune response (in group three G3) stimulated by the mixture (WSA and mycotoxoid), which revealed a significant increase in both IL-17 and IFN- $\gamma$. After experimental infection, the sero-analysis showed a significant increase in IL-17 and IFN- $\gamma$ serum levels compared with the mixture-immunized group which showed no significant increases. In addition, the histopathologic sections illustrated severe chronic inflammation with a typical fungal granulomatous reaction in the prostate glands and kidneys compared with the WSA-immunized groups which showed mild histological reactions. Finally, we conclude that A. flavus is a serious opportunistic pathogen that can disseminate into genitourinary organs inducing severe pathologic lesions and even death. Moreover, we found that immunization by WSA and mycotoxoid can significantly reduce both immune and histopathological effects of A. flavus and its mycotoxins.
\end{abstract}

DOI: $10.33899 /$ ijvs.2021.131580.1974, (๑) Authors, 2021, College of Veterinary Medicine, University of Mosul.

This is an open access article under the CC BY 4.0 license (http://creativecommons.org/licenses/by/4.0/).

\section{Introduction}

Urinary tract infection by fungus commonly increased as a result of frequently use of antibiotics, immunocompromised conditions and catheterization. For decades, the kidney is considered as a target organ of $A$. flavus infection. Some therapeutic agents are linked to unanticipated increases in opportunistic fungal infections to the genitourinary system. Primary genitourinary invasive aspergillosis was presented in a patient with chronic lymphocytic leukemia report (1). Also, some males have been diagnosed with concurrent prostatic and renal aspergillosis (2). As a result, there is a scarcity of information on diagnostic methods for determining systemic involvement in cases of prostatic aspergillosis. We presented a patient with systemic aspergillosis with main genitourinary symptoms, however, appeare to be immunologically normal (3). A patient with chronic renal illness who presents with occasional abdominal pain was misdiagnosed as aspergillosis. The pathological results of the fungal ball in the bladder confirmed the diagnosis of aspergillosis. Moreover, it produces severe toxic secondary metabolites, including mycotoxin, particularly aflatoxins which classified as carcinogenic by consumption of 
contaminated cereals like nuts and corns leading to large economic losses (4). Vaccination against fungi including Aspergillus species is an issue, since, the most susceptible people are those whom immunocompromised, particularly those with neutropenia, leukemias. Vaccination against specific mycotoxins could be proposed to prevent mycotoxicosis in livestock and mycotoxins contaminated food from an animal sources (5). Therefore, many studies were performed to develop a new effective fungal vaccine depending on well understanding immune response against pathogenic fungi (6).

This study aimed to reduce not only the pathological effects of the A. flavus, but also its mycotoxins via immunization trails.

\section{Materials and methods}

PCR using Aspergillus flavus specific gene primers RtfA Specific gene primers (RtfA), FW (5'-GTT CCC TTT CGT TGC TTG TTC AGA CTC-3') and RV (5'-CAG TCG ACT TGG TGT CCA GTG ATCC-3') that has a product length of $263 \mathrm{bp}$ (7) was used for virulence examination of the selected isolate to the experimental infection. The PCR reactions were programmed with specific conditions, (initial denaturation at $95^{\circ} \mathrm{C}$ for $5 \mathrm{~min}$. Denaturation at $95^{\circ} \mathrm{C}$ for 45 sec., annealing at $62^{\circ} \mathrm{C}$ for $45 \mathrm{sec}$. and elongation $72^{\circ} \mathrm{C}$ for $45 \mathrm{sec}$. and final extension at $72^{\circ} \mathrm{C}$ for $10 \mathrm{~min}$.

\section{Modification of aflatoxins to aflatoxoid (Detoxification)}

The crude extracted mycotoxin was detoxified by ammoniation as described by with some modifications, that the aflatoxin was placed in a sealed glass tube, $20 \mathrm{ml}$ in capacity, which mixed with $1 \mathrm{~mL}$ ammonia solution $\mathrm{NH}_{3}$ $25 \%$ at $100^{\circ} \mathrm{C}$ for 1 hour and under 40 Psi pressure (8).

\section{Whole sonicated antigen preparation}

Whole sonicated antigen of A. flavus was prepared as follow: A 5-7 old days of A. flavus growing on Sabouraud dextrose agar plates at $37^{\circ} \mathrm{C}$ was collected into sterile plain tube containing $0.9 \%$ normal saline included Tween 80 $(0.1 \%)$.

The conidial clumps were interspersed by glass beads ( 3 $\mathrm{mm}$ in size), and then washed twice and resuspended with the same solution $0.01 \%$ Tween 80 included in $0.9 \%$ saline. This method resulted in conidial suspension free from mycelia with $>95 \%$ single conidia. The hemocytometer was used to set conidial numbers, then, the viability was evaluated by platting culture on SDA.

The suspension was frozen at $-80^{\circ} \mathrm{C}$ and then the yields was sonicated three times, for two minutes, on ice pieces, with a Bronwill BioSonik III Sonicator at 30\% intensity level using a $4 \mathrm{~mm}$ flat bottom Sonicator tip. Moreover, the product was frozen at $-80^{\circ} \mathrm{C}$ and quickly thawed at $37^{\circ} \mathrm{C}$ between the cycles. The sonicated Aspergillus flavus was aliquoted and frozen at $-80^{\circ} \mathrm{C}$ until use (9).

\section{Experimental animals}

Fifty of albino male rats whose 200-250 grams of weighing and 8-10 weeks of were bought from Baghdad center of animal laboratory. These rats were housed in a clean and suitable cag with a good environment and ventilation under strict policy $23 \pm 2^{\circ} \mathrm{C}$ and $12 \mathrm{~h}$ light/ $12 \mathrm{~h}$ dark (10). The rats were managed well in the unite of the experimental laboratory animals by which they had acclimatization for two weeks before the beginning of experiment. They were given standard pellet feed and water was ad libitum $(11,12)$.

\section{Design of experimental study}

After preparation of immunization suspension and concentrations of all components, which were subjected as $100 \mu \mathrm{l}$ of whole sonicated antigen (13), mycotoxoid 0.25 $\mathrm{mg} / 100 \mu \mathrm{L}$ with slight modification. These components were either mixed together or separated, depending on the immunized group. The animals were divided into five groups; each group has 10 rats as follow: Negative control group (G1): was received only phosphate buffer saline (PBS) containing tween $20100 \mu \mathrm{L} /$ animal at times of immunizations. Group of positive control (G2): injected, intraperitoneally with challenge dose $10^{6}$ conidia/ $0.5 \mathrm{~mL}$ (14) at time of infection. G3: Immunized with sonicated Ag and mycotoxoid, $100 \mu \mathrm{L}$ per animal. G4: Immunized with sonicated $\mathrm{Ag}$ alone, at $100 \mu \mathrm{L}$ per animal. G5: Immunized with mycotoxoid alone, at $100 \mu \mathrm{L}$ per animal. The animals were immunized with two doses via subcutaneous injection, with two weeks' interval.

\section{Blood collection and serum separation}

During $28^{\text {th }}$ day of post-immunization and $20^{\text {th }}$ day postinfection blood samples were collected from all groups for ELISA tests of IL-17 and IFN- $\gamma$ detection. The blood was collected into gel tube and the sera was separated by centrifuge at $4000 \mathrm{rpm}$ for 10 minutes, then the sera (upper layers) were collected in $2 \mathrm{ml}$ Eppendorf tubes and placed in deep freeze until use (14).

\section{Immunosuppression and antibiotic administration}

We were relied on both methods of (15) in these procedures as the following: Prior to infection (challenge) and 2 weeks after the second dose of immunization, cortisone was injected $2.5 \mathrm{mg}$ subcutaneous doses in consecutive six days. To prevent bacterial infection, rats were injected with Levofloxacin $200 \mu \mathrm{g}$ subcutaneously, 1hour before challenge.

\section{Infectious challenge test}

After 6 days of immunosuppression and at a day, 35 post-immunizations, the immunized rats were injected intraperitoneally with challenge dose $1 \times 10^{6} / 0.5 \mathrm{~mL}$ viable conidia/ rat, while the negative control group was injected I.P with $0.5 \mathrm{~mL}$ of sterile PBS containing tween 20. Animals 
were left for 36 hours after infection until signs and symptoms exist. Rats were under supervision during the whole experiment. Diarrhea, constipation, hemorrhage, and death were documented whenever being seen. All animals were sacrificed after 20 days post-infection (On day-55 post immunization) (Figure 1), and the targeted organs were taken for isolation of fungus and for histopathology procedures (16).

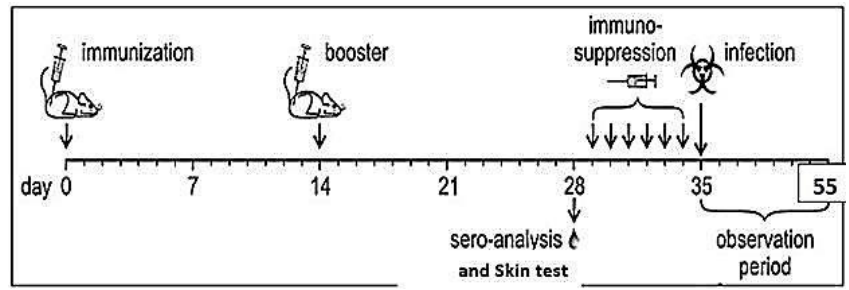

Figure 1: Scheme of the experiment included first immunization, booster dose and immunosuppression of rats, challenge and observational period after infection (16).

Determination of serum cytokines (IFN- $\gamma$ and IL-17) levels using ELISA test (Sandwich type Ab-Ag-Ab):

It was performed based on manufacture policy (Elabscience) at which ELISA was conducted in vitro for determination the quantity of (Rat IL-17 or Rat IFN- $\gamma$ ) levels in serum.

\section{Principles of procedure}

The plates of ELISA were precoated by antibodies specific for Rat IL-17 or Rat IFN- $\gamma$. Standards or serum samples were placed in wells of the precoated plates and allowed to react with their specific target antibodies.

\section{Assay procedure}

Serum samples and reagents were transported to room temperature $18-25^{\circ} \mathrm{C}$ before using. A $100 \mu \mathrm{l}$ was added of each blanks, slandered or samples into their wells and mixed gently, then, the plates were covered by sealer and put in incubator at $37^{\circ} \mathrm{C}$ for $90 \mathrm{~min}$. The excessive liquid was removed from all tested wells, but without washing, then immediately, a $100 \mu \mathrm{L}$ of detection antibody (Biotinylated) working solution was added to all tested wells and covered by the sealer and incubated for 60 minutes at $37^{\circ} \mathrm{C}$. The plate was washed by aspirating of each well and washing by filling each well with Wash Buffer. This process was repeated three times. After the last washing, the plate was put upside and hit on a thick absorbent paper. A $100 \mu \mathrm{L}$ of avidin horseradish peroxidase conjugate added into each tested well. The Plate was covered with sealer and incubated for 30 minutes at $37^{\circ} \mathrm{C}$. The washing process was repeated 5 times. A $90 \mu \mathrm{L}$ of substrate solution was added into each well, then covered, and Incubated at $37^{\circ} \mathrm{C}$ for 15 minutes. For stopping the reactions, a $50 \mu \mathrm{L}$ of stopping solution was added into all tested wells, by which, yellow discoloration appeared immediately. The absorbance on wave length $(450 \mathrm{~nm})$ was measured using a micro-plate reader (Biochrom Asys Expert Plus) immediately.

\section{Histopathology}

The animals were sacrificed after two weeks and the target organs were harvested, fixed in formaldehyde $10 \%$ for $48 \mathrm{hrs}$ and pieces of organs had been taken and processed by auto-tissue processing machine including dehydration, by ascending series alcohol, clearance, by xylene and impregnation, with liquid paraffin. After that, the tissues were embedded in paraffin blocks, sectioned by microtome at thickness of $5 \mu \mathrm{m}$, mounted on glass slides, and stained with routine stains with hematoxylin and eosin and special stains, periodic acid Schiff (PAS), and covered by coverslips. Finally, the slides examined under light microscope comparing with normal control group (11).

\section{Procedure of periodic acid Schiff (PAS) staining}

Xylene was used to deparaffinize the histopathological sections for 5 minutes for three changes. The sections, then, were placed into alcohol for 5 minutes of two changes. The sections placed into water jar. Adding the oxidizing agent periodic acid for 10 minutes. The sections, then, washed completely by tap water and rinsed by distilled water. The sections stained by Schiff's solution about 20 minutes. Section were completely washed again in distilled water. The sections, then, progressively stained with counter stain Cole`s hematoxylin for 10 minutes. They were thoroughly washed by tap water. Sections, then, blued in tap water. The slide sections, then, dehydrated by alcohol, cleared by xylene and mounted with DPX. Finally, the stained slides section was examined using light microscope (11).

\section{Statistical analysis}

Statistical analysis was performed using IBM statistical package for social science, IBM SPSS Statistics version 23.

\section{Results}

\section{Detection the gene of pathogenicity (RtfA)}

The selected A. flavus isolate for experimental infection was positive for gene of pathogenicity (RtfA) of A. flavus (Figure 2).

\section{Clinical signs and symptoms after infection}

Intraperitoneally infected rats groups with challenge dose $1 \times 10^{6}$ viable conidia $/ 0.5 \mathrm{~mL}$ of $A$. flavus were revealed signs and symptoms post-infection. Rats of positive control group were presented with signs such as lethargy and decreasing food intake after 36 hours of fungal infection, while this group and non-sonicated antigen-immunized group (G5) were developed signs and symptoms $72 \mathrm{hrs}$. post-infection. The recorded signs and symptoms were 
tachycardia, tachypnea, diarrhea, wasting, incoordination, dehydration, dirty eyes and nostrils, ruffled hairs and recumbency in comparison with rats of sonicated antigenimmunized groups and negative control group.

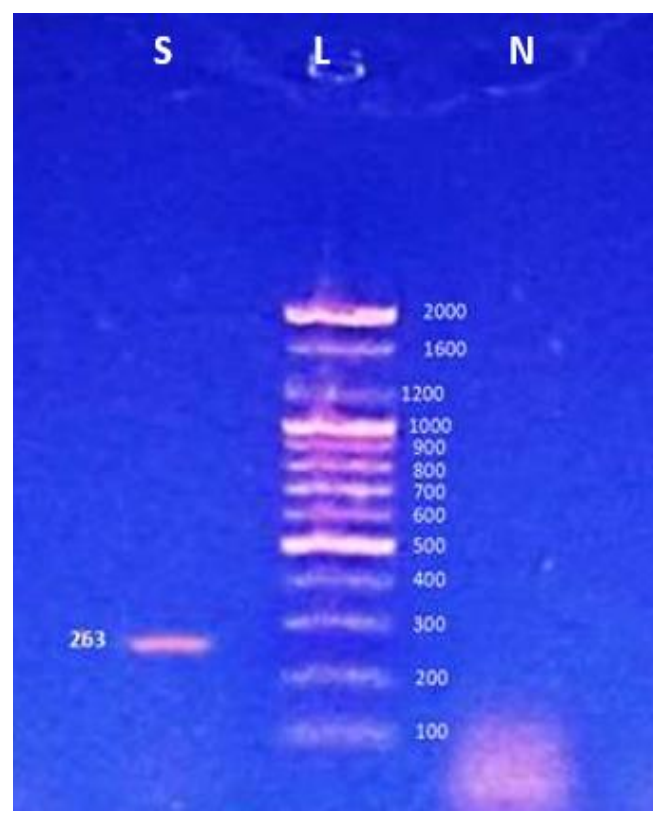

Figure 2: Shows positive result of specific primers RtfA gene (263 bp), a gene of pathogenicity of A. flavus isolate. $\mathrm{L}$, the ladder. $\mathrm{N}$, the negative result for other sample.

\section{ELISA test for interleukin-17}

On the day $28^{\text {th }}$ of post-immunization, serum levels $(\mathrm{pg} / \mathrm{ml})$ of IL-17 were significantly increased in immunized groups G3, G4 in comparison with G5 which in turn showed significant increases compared with G1. In contrast, serum levels of IL-17 were significantly increased in G2 and G5 on the day $20^{\text {th }}$ of post-infection compared with G1, G3 and G4 (Table 1).

\section{ELISA test for Interferon- $\gamma($ IFN- $\gamma)$}

On the day $28^{\text {th }}$ of post-immunization, serum level $(\mathrm{pg} / \mathrm{ml})$ of IFN- $\gamma$ were significantly increased in G3, and G4 in comparison with G1 group and G5. In contrast, G5 showed significant increases on the day $20^{\text {th }}$ of postinfection compared with G1, G3, and G4. On the other hand, the positive control group G2 was showed significant increases in serum levels of IFN- $\gamma$ on the day $20^{\text {th }}$ of postinfection compared with all groups (Table 2).

\section{Kidney histopathology}

The kidneys were severely invaded by fungal infection where there was high growth and colonization of A. flavus inside the renal pelvis. Infiltration of different types of inflammatory cells were seen in this growth. Therefore, resulted in distention and compression of the surrounding tissue of both cortex and medulla. Massive infiltration of chronic inflammatory cells was also clearly detected. The changes were observed in G2 and G5 compared with other groups, which were within the normal criteria (Figures 3-6)

Table 1: Shows IL-17 serum levels ( $\mathrm{pg} / \mathrm{ml})$ in groups on the day $28^{\text {th }}$ of pot-immunization and on the day $20^{\text {th }}$ of post-infection compared with control group

\begin{tabular}{lccccc}
\hline \multirow{2}{*}{ Periods } & \multicolumn{5}{c}{ mean $\pm \mathrm{SE}$ (n=6 animal at each group) } \\
\cline { 2 - 6 } & $\mathrm{G} 1$ & $\mathrm{G} 2$ & $\mathrm{G} 3$ & $\mathrm{G} 4$ & $\mathrm{G} 5$ \\
\hline \multirow{2}{*}{ Post immune } & $10.93 \pm 0.566$ & $11.71 \pm 0.867$ & $27.05 \pm 1.387$ & $26.66 \pm 1.304$ & $17.07 \pm 2.058$ \\
Post infect & $\mathrm{C} \mathrm{a}$ & $\mathrm{C} \mathrm{a}$ & $\mathrm{A} \mathrm{a}$ & $\mathrm{A} \mathrm{a}$ & $\mathrm{B} \mathrm{a}$ \\
& $10.93 \pm 0.566$ & $60.007 \pm 1.685$ & $27.46 \pm 1.856$ & $26.65 \pm 1.115$ & $37.87 \pm 4.717$ \\
& $\mathrm{C} \mathrm{a}$ & $\mathrm{D} \mathrm{c}$ & $\mathrm{A} \mathrm{a}$ & $\mathrm{A} \mathrm{a}$ & $\mathrm{B} \mathrm{b}$ \\
\hline
\end{tabular}

Capital letters refers to presence of significant differences within a row. Small letters refer to significant differences within a column at $\mathrm{P}<0.05$.

Table 2: Shows serum levels of IFN- $\gamma(\mathrm{pg} / \mathrm{ml})$ in immunized groups on the day $28^{\text {th }}$ of post-immunization and on the day $20^{\text {th }}$ of post-infection compared with control groups

\begin{tabular}{lccccc}
\hline \multirow{2}{*}{ Periods } & \multicolumn{5}{c}{ mean \pm SE $(\mathrm{n}=6$ animal at each group) } \\
\cline { 2 - 6 } & G1 & G2 & G3 & G4 & G5 \\
\hline $28^{\text {th }}$ days & $29.924 \pm 2.113$ & $29.227 \pm 2.775$ & $59.250 \pm 6.426$ & $51.236 \pm 3.153$ & $34.641 \pm 1.623$ \\
Post immune & $\mathrm{C} \mathrm{a}$ & $\mathrm{C} \mathrm{a}$ & $\mathrm{B} \mathrm{a}$ & $\mathrm{B} \mathrm{a}$ & $\mathrm{C} \mathrm{a}$ \\
$20^{\text {th }}$ day & $29.046 \pm 1.658$ & $165.301 \pm 35.242$ & $60.330 \pm 5.955$ & $50.332 \pm 3.176$ & $136.501 \pm 7.205$ \\
Post infect & $\mathrm{C} \mathrm{a}$ & $\mathrm{D} \mathrm{c}$ & $\mathrm{B} \mathrm{a}$ & $\mathrm{B} \mathrm{a}$ & $\mathrm{C} \mathrm{b}$ \\
\hline
\end{tabular}

Capital letters refers to presence of significant differences within a row at $\mathrm{P}<0.05$. Small letters refer to significant differences within a column at $\mathrm{P}<0.05$. 

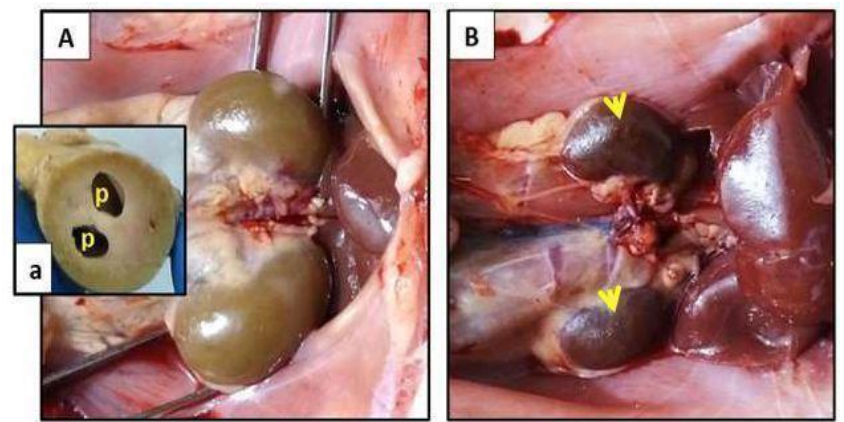

Figure 3: A. Gross appearance of kidneys for (G5) illustrating severe bilateral enlargement of kidneys which appears with intensive paleness in color compared with normal control kidneys (head arrows) in (B). a. Transverse gross section of affected kidney shows wide distention of renal pelvis $(\mathrm{P})$.
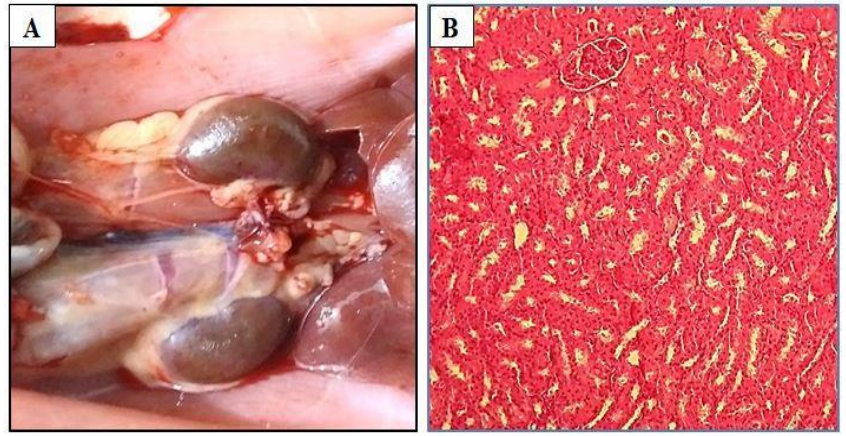

Figure 4: A. Gross appearance of kidneys belong to immunized group (G3) appeared within normal limits. B. Histopathological sections of renal cortex for (G3) appears only mild degeneration in renal tubules compared with other affected groups. H\&E, 100X.

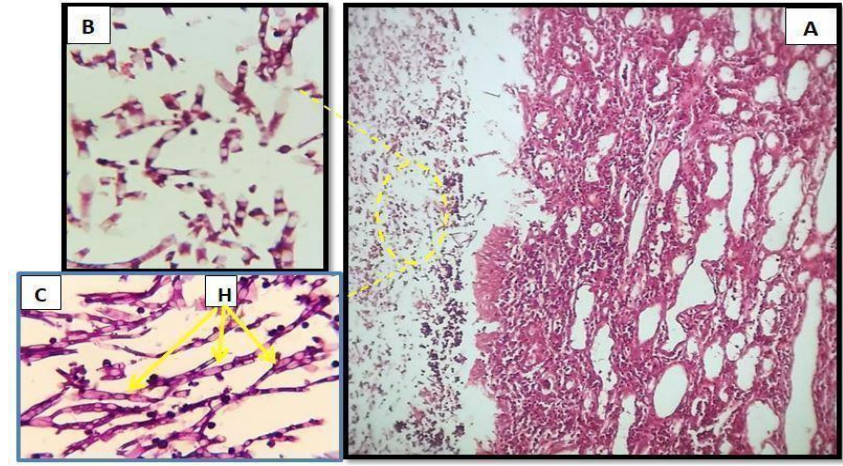

Figure 5: A. Histopathological sections of (G5) showed the fungal infection in distended renal pelvis 40X. B. High magnification of A. flavus septated hyphae H\&E.400X. C. Indicated by branched and septate hyphae $(\mathrm{H})$ invaded by different types of inflammatory cells, PAS stain.

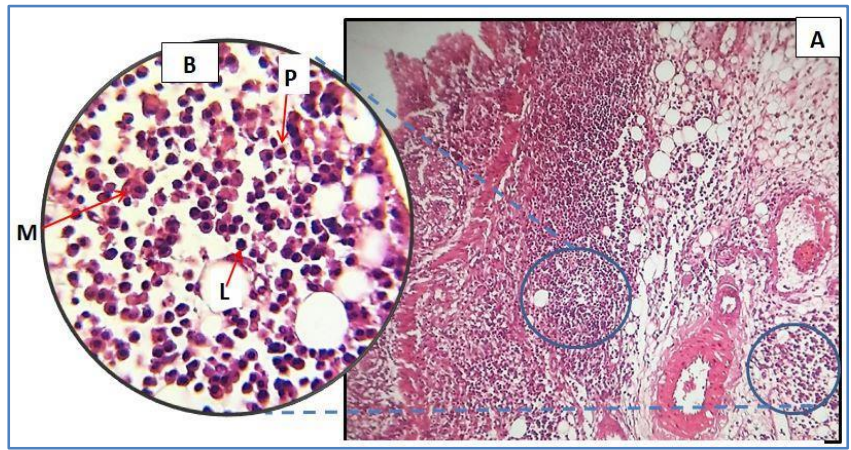

Figure 6: A, B. Histopathological sections reveals severe chronic nephritis in G5 because of fungal infection characterized by heavy infiltration of chronic inflammatory cells including lymphocytes (L), macrophages (M), plasma cells $(\mathrm{P})$ and edematous fluids present as well. H\&E, 400X

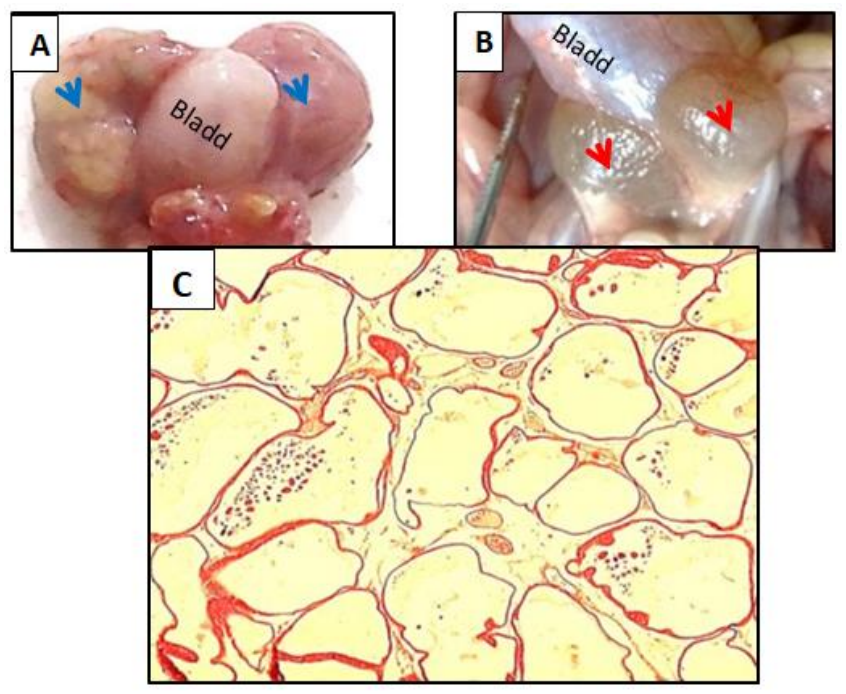

Figure 7: A. Gross appearance shows fungal invasion for prostate glands in (G5) which have a yellowish-white nodular lesions containing cheesy like material (blue arrows). B Gross appearance for negative control group shows the normal color (greyish) and normal, regular shape and size (red arrows). C. Histological section of prostate gland belong to group (G3) illustrates the normal glandular histological structure. H\&E, 40X.

\section{Prostate glands histopathology}

The prostate glands presented with a severe fungal invasion that was grossly observed in the G5 group and characterized by severe enlargement, congestion and the presence of yellowish-white nodular lesion containing cheesy like material, in contrast to the prostate glands of negative control and G3 and G4, which were have normal color (greyish) with normal size and regular shape. Microscopic examination revealed multiple typical fungal 
pyogenic granulomas indicated by the presence of fungal hyphae of A. flavus in the center of caseation surrounded by a massive polymorphonuclear cell with the presence of many multinucleated giant cells for G5 compared with negative control group and G3 (Figures 7-9).

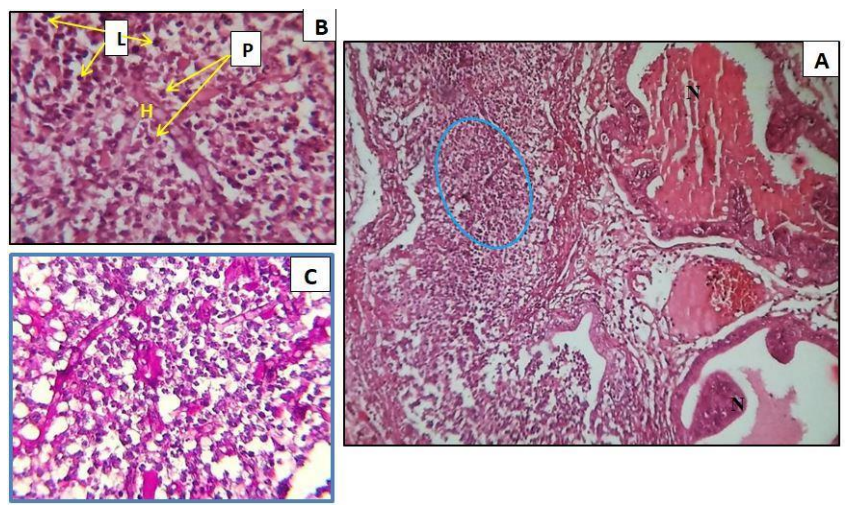

Figure 8: A. Histopathological section shows invasion of $A$. flavus to prostate gland in group (G5) destructing some of glandular structures (circle) inducing granulomatous inflammation compared with adjacent normal glandular structures $(\mathrm{N})$ 40X. B. Intermediate magnification shows the fungal hyphae (circle) surrounded with massive inflammatory cells $100 X$. H\&E. C. illustrates the branched and septate hyphae $(\mathrm{H})$ of $A$. flavus surrounded with mixed of polymorphonuclear cells $(\mathrm{P})$, necrotic debris and other chronic inflammatory cells, PAS stain. 400X.

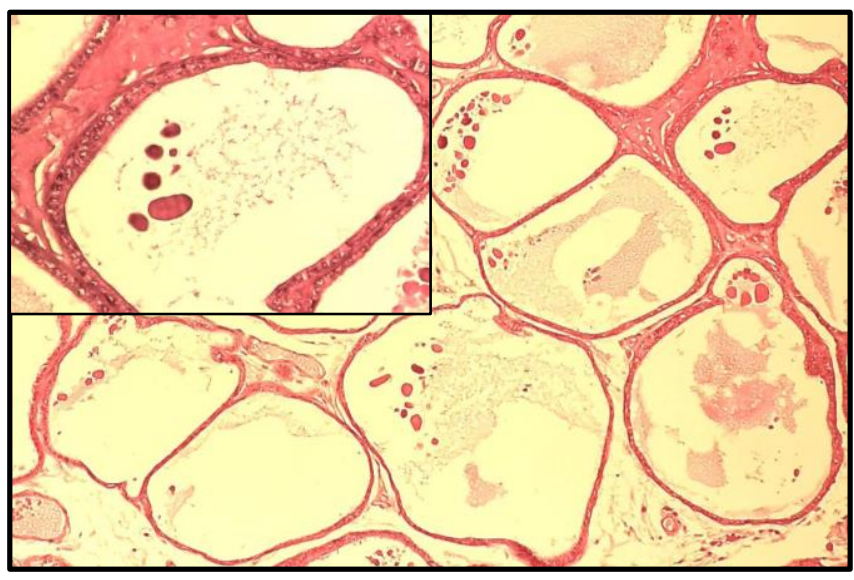

Figure 9: A. Histopathological section of prostate gland for (G3) shows its histological structure within normal limits and without fungal invasion, 100X. B. High magnification illustrates the glandular epithelial cells of normssal prostate, 400X, H\&E.

\section{Discussion}

Generally, the more affected groups in the present experimental study were the non-sonicated antigen immunized group G5 and positive control group G2 that manifested with low protective response against $A$. flavus fungal infection in contrast to sonicated antigen immunized groups G3 and G4. The protective immune response of G3 and G4 against $A$. flavus infection is probably attributable to the high stimulation and activation of Aspergillus $\mathrm{T}$ lymphocytes. Since, Aspergillus cell wall antigens stimulates Aspergillus specialized $\mathrm{T}$ lymphocytes to produce both IFN- $\gamma$ and IL-17 (12).

The clinical signs and symptoms were severely observed in the positive control and less severity in nonsonicated antigens immunized group G5 compared with negative control and sonicated antigens immunized groups G3 and G4. These signs and symptoms were similar to those presented study of Martin et al. (13) who observed lethargy, dehydration, emaciation, loss of appetite, restlessness, neurologic and respiratory disorders in affected chickens. Absence of the signs and symptoms in G3 and G4 may be due to the activation of cellular and humoral immunity against fungal infection, thus, inducing high concentrations of IFN- $\gamma$ and other cytokines, which in turn stimulate phagocytic activities of macrophages, dendrocytes and neutrophils.

Enlargement, discoloration and gross changes of the target organs, kidneys may be attributed to the fungal invasion or severe toxic effects of the aflatoxins. In addition, researchers recorded an enlargement of the liver and kidney in the broilers due to aflatoxin B1 (AFB1) toxicity (14). Besides, Prostatic enlargement was noticed in the tested rats and this may due to the fungal invasion as noticed by.

There are a significant increase in serum levels of both IFN- $\gamma$ and IL-17 in this study, post-immunization period in groups G3, G4 and G5, while during post-infection period in G5 and positive control groups. However, there are no significant increases in IFN- $\gamma$ levels in G5 at the postimmunization period compared with negative control group might be due to differences in activation of acquired immune cells particularly, $T$ helper lymphocyte interaction with antigen presenting cells (APCs), which responsible to produce these cytokines IFN- $\gamma$ and IL-17. This explanation was compatible with the results of fungal immunological studies (15).

Moreover, cytokines that results from the interaction between $\mathrm{CD}^{+}$lymphocytes and antigen presenting cells lead to differentiation of $\mathrm{CD}^{+}$cells into certain subtype of Th cells through stimulation of various signal transductions as STAT1/STAT4 required for Th1 differentiation and ROR-yt/STAT3 required for Th17 differentiation (16). These cells are the main producers for IFN- $\gamma$, and IL-17 and IL-22, respectively, which in turn produce protective immune response, by which, IFN- $\gamma$ stimulates the cellular immunity and phagocytosis, while IL-17 and IL-22 stimulate neutrophilic recruitments and activation which produce defensins (a microbial inhibitor peptides). Thus, 
the elevation of IFN- $\gamma$ and IL-17 in post-immunization period and post-infection with A. flavus were comported with normal immune response against Aspergillus infection reported by many studies such as (17) who presented that IFN- $\gamma$ treated neutrophils resulted to enhance the destruction of A. flavus hyphae and elevation of ROS from neutrophils.

Dissemination of fungal infection to the kidneys, in particular, renal pelvic in G5 as well as infiltration of different types of inflammatory cells predominantly neutrophils and macrophages, was similar to those seen via intravenous infection of mice with A. flavus. Hyphae were located in the pelvic area surrounded by PMNs. Presence a heavy infiltration of neutrophils to the site of the fungal infection also noticed by (18). Furthermore, a case report was diagnosed in a 32 years immunocompetent old patient with severe A. flavus Urinary Tract Infections. The patient was with a long duration of ureteral stone and urinary tract catheterization. Bilateral hydronephrosis, fungal sepsis, and urine retention are being occurred because of ureteral obstruction followed by kidney failure due to A. flavus infection (19).

Disseminated prostatic aspergillosis was reported even in immunocompetent patients who had a urethral transection process, which was diagnosed via isolation of $A$. flavus from urine sample (3). The current study found $A$. flavus invasion reach into the prostate gland causing multiple granulomatous lesions. These were observed only in non-sonicated antigen immunized groups G5 which received a mycotoxoid only. This result had an agreement with previous studies. The urinary tract invasion is mostly involved prostate glands (20) and usually caused by systemic hematogenous spreading. Aspergillus prostitis with microabscessations (21).

Recently, A. flavus has occupied the highest percentage $13.5 \%$ of 37 among mold-contaminated milk samples sample (22). Therefore, milk may have considered to be a serious source of infection by this fungus. Considered the Aspergilli as one of effective fermenting microorganisms which may use for inhibition of pathogenic bacterial growth (23). In addition, (24) mentioned that Aspergillus species was recorded as one cause of urinary system organs, in particular the urinary bladder in calves.

\section{Conclusion}

We conclude that A. flavus is a serious opportunistic pathogen that can disseminate into genitourinary organs inducing severe pathologic lesions and even death. On the other hand, the immune responses and antigenic memorization that induced in the sonicated antigenimmunized groups G3 and G4 were play an important role in the protection against fungal infection, regardless the toxic effects of aflatoxins. Thus, using the mixture of both sonicated antigen and modified mycotoxin in immunization might give a promise protection against serious pathogenic or opportunistic fungi; even in immunocompromised patients. In addition, efficient vaccine can produce active natural and acquired immunity against certain pathogen via induces cellular memorization which enables to eliminate the same pathogen.

\section{Conflict of interest}

The authors declare that there are no conflicts of interest regarding the publication of this manuscript.

\section{Acknowledgment}

I would like to express my deep thanks to my supervisor, Assist. Prof. Dr. Inam Badr Faleh for her professional insights, and encouraging attitude. I would like to express my gratitude to the deanery of the College of Medicine/University of Misan Prof. Dr. Yassin Aubiad for his valuable cooperation and support. Deep appreciation and sincerely thanks are paid to Assist. Prof. Dr. Abbas Naji Balasim Al-Saadi and Assist. Prof. Dr. Mukhalald AbdulKareem Al-rubyaai, who inspired me inside the pathology lab.

\section{References}

1. Albin OR, Soper N, Khurana I, Kauffman CA. Invasive genitourinary aspergillosis in a patient with chronic lymphocytic leukemia treated with venetoclax: Case report and review of the literature. Open Forum Infect Dis. 2019;6(11):1-4. DOI: 10.1093/ofid/ofz457

2. Ansari MS, Nabi G, Singh I, Hemal AK, Bhan A:Mycotic abdominal aortic aneurysm: A fatal sequel to concomitant prostatic and renal aspergillosis. Urol Int. 2001;66:36-37. DOI: 10.1159/000056561

3. Ludwig M, Schneider H, Lohmeyer J, Ermert L, Sziegoleit A, Lommel D, Weldner W. Systemic aspergillosis with predominant genitourinary manifestations in an immunocompetent man: What we can learn from a disastrous follow-up. Infect. 2005;33(2):90-2. DOI: 10.1007/s15010-005-4070-z

4. Seyedmousavi S, Guillot J, Arné P, De Hoog GS, Mouton JW, Melchers WJG, abd Verweij PE. Aspergillus and aspergilosis in a wild and domestic animals: A global health concern with parallels to human disease. Med Mycol. 2015;53(8):765-797. DOI: 10.1093/mmy/myv067

5. Ascioglu S, Rex JH, Pauw Bd, Bennett JE, Bille J, Crokaert F, Denning DW, Donnelly JP. Defining Opportunistic Invasive Fungal infections in immunocompromised patients with cancer and hematopoietic Stem cell transplants: An international consensus. Clin Infect Dis. 2002;34:7-14. DOI: 10.1086/323335

6. Nami S, Mohammadi R, Vakili M, Khezripour K, Mirzaei H, Morovati $\mathrm{H}$. Fungal vaccine, mechanism of actions and immunology: A comprehensive Review. Biomed Pharmacother. 2019;109:333-334. DOI: 10.1016/j.biopha.2018.10.075

7. Lohmar JM, Hrris-Coward PY, Cary JW, Dhingra S, Calvo AM. RtfA, a putative RNA-Pol II transcription elongation factor, is necessary for normal morphological and chemical development in Aspergillus flavus. Appl Microbiol Biotechnol. 2016;100(11):50295041. DOI: 10.1007/s00253-016-7418-7

8. Bailey GS, Price RL, Park DL, Hendricks JD. Effect of ammoniation of aflatoxin B1contaminated cottonseed feedstock on the aflatoxin M1 content of cow's milk and hepatocarcinogenicityin the troutbioassay. Chem Toxic. 1994;32(8):707-715. DOI: 10.1016/s02786915(09)80003-3 
9. Ito JI, Lyons JM. Vaccination of corticosteroid immunosuppressed mice against invasive pulmonary aspergillosis. J Infect Dis. 2002;186:869-871. DOI: $10.1086 / 342509$

10. Udeani TK, Okwuosa CN, Adiele EU. Effect of Aspergillus flavus on the liver of experimental rats administered with anti-retroviral drugs. Am J Phytomed Clin Therapeut. 2013;(6):443-456. [available at]

11. Al-Mahmood SS. Improving light microscopic detection of collagen by trichrome stain modification. Iraqi J Vet Sci. 2020; 34(2):273-281. DOI: 10.33899 /ijvs.2019.126176.1256

12. Potenza L, Vallerini D, Barozzi P, Leonardo P, Daniela V, Patrizia B, Giovanni R, Fabio F, Anne B, Remi B. Characterization of specific immune responses to different Aspergillus antigens during the course of invasive aspergillosis in hematologic patients. PLoS. 2013;1(8):74326. DOI: 10.1371/journal.pone.0074326

13. Martin MP, Bouck KP, Helm J, Dykstra MJ, Wages DP, Barnes HJ. Disseminated Aspergillus flavus Infection in broiler breeder pullets. Avi Dis. 2007;51:626-631. DOI: 10.1637/00052086(2007)51[626:DAFIIB]2.0.CO;2

14. Saleemia MK, Ashrafa K, Gula ST, Naseema MN M, Sajida S, Mohsina M, Heb C, Zubairc M, Khan A. Toxicopathological effects of feeding aflatoxins B1 in broilers and its ameliosration with indigenous mycotoxin binder. Ecotoxicol Environ Saf. 2020;187:109712. DOI: 10.1637/00052086(2007)51[626:DAFIIB]2.0.CO;2

15. Dehghan P, Tolouiea S, Baradaranb B, Namic S, Morovati H. TLR-2, IL-10 and IL-17-mediated immunity in experimental chemotherapy murine model of systemic candidiasis; cyclophosphamides' impact and roles. Microbiol Pathol. 2018;119:183-192. DOI: 10.1016/j.micpath.2018.04.026

16. Salazar FGD. Antifungal innate immunity: A perspective from the last 10 years. J Innate Immunol. 2018;1-25. DOI: 10.1159/000488539

17. Gil-Lamaignere C, Winn RM, Simitsopoulou M, Maloukou A, Walsh TJ, Roilides E. Inteferon gamma and granulocyte-macrophage colonystimulating factor augment the antifungal activity of human polymorphonuclear leukocytes against Scedosporium spp.: Comparison with Aspergillus spp. Med Mycol. 2005;43:253-260. DOI: $10.1080 / 13693780412331271072$

18. Cua-Daniel J, Tato-Cristina M. Innate IL-17-producing cells:the sentinels of the immune system. Nat Rev Immunol. 2010;10:479-89. DOI: $10.1038 /$ nri2800

19. Smaldone MC, Cannon GM, Benoit RM. Case report: bilateral ureteral obstruction secondary to Aspergillus bezoars. J Endourol. 2006;20:318-20. DOI: 10.1089/end.2006.20.318

20. Hemal AK, Talwar M, Dinda A. Concomitant renal and prostatic aspergillosis. Int Urol Nephrol. 1999;31:157-62. DOI: 10.1023/a:1007116523000

21. Fisher ME, Nisenbaum HL, Axel L, Broderick GA. Prostatic abscess due to Aspergillus fumigatus: TRUS and MR Imaging Findings. J Ultrasoun Med. 1998;17:181-184. DOI: 10.7863/jum.1998.17.3.181

22. Yassein SN, Zghair ZR. Experimental infection in mice with Acremonium spp. mold and Rhodotorula spp. yeast isolated from cow's milk. Iraqi J Vet Sci. 2020;34(1):165-171. DOI: 10.33899/ijvs.2019.125718.1138.

23. Hamad MA, Hussein SA, Mahmmoud EN, Al-Aalim AM. The inhibitory role of effective microorganisms on the growth of pathogenic bacteria. Iraqi J Vet Sci. 2020;34(1):153-158. DOI: 10.33899/ijvs.2019.125653.1123

24. Saeed MG. Investigation of urinary bladder lesions of slaughtered local bovine calves in Mosul city. Iraqi J Vet Sci. 2020;34(1):45-51. DOI: $10.33899 /$ ijvs.2019.125541.1063

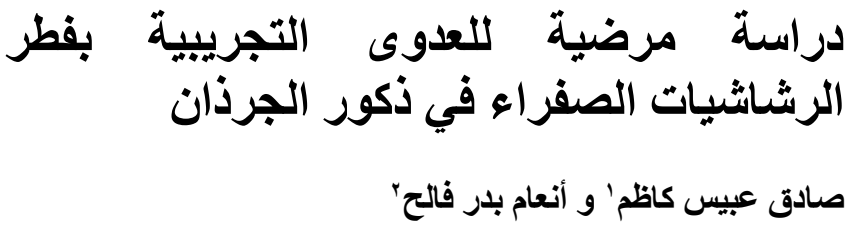

'فرع الأمراض والطب العدلي، كلية الطب، جامعة ميسان، ميسان،

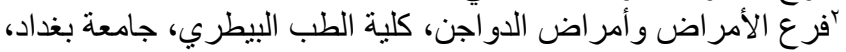

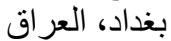

الخلاصة

نظراً لانتشار جراثيم الرشاشيات الصفراء و المخاطر الكبيرة

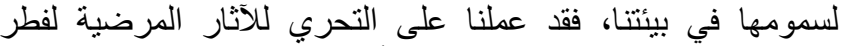
الرشاشيات الصفراء على بعض الأعضاء في الجرذان المختي المختبرية

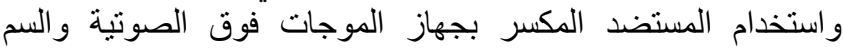

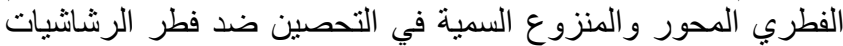

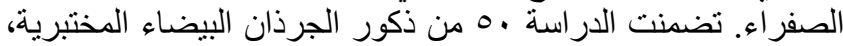

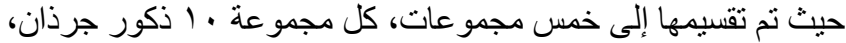

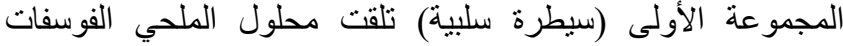

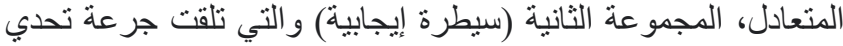

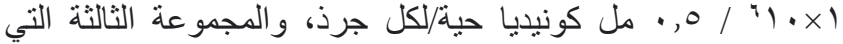

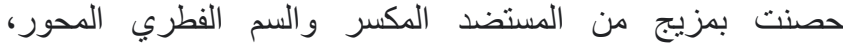
و المجموعة الر ابعة التي حصنت بالمستضد المكسر فقط، والمجموعة

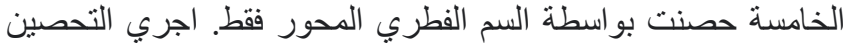

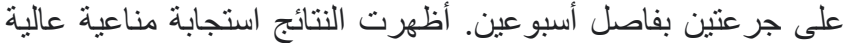
حفز ها الخليط (المستضد المكسر و السم الفطري المحور)، حيث كانت هنالك زيادات كبيرة في كل من الانترلوكين-V الإل والانترفيرون-كاما. وبعد الإصسابة التجريبية أظهر التحليل المصلي من زيلي زيادات معنوية في مستويات الانترلوكين-1V والانترفيرون- كاما في المصل مقارنة

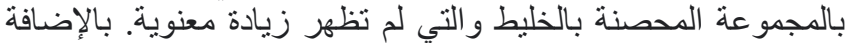

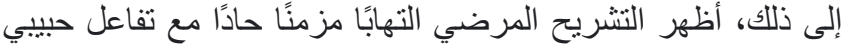

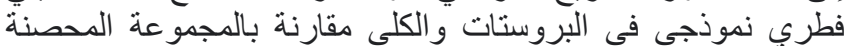

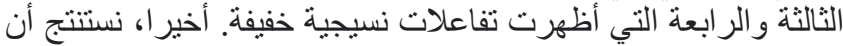

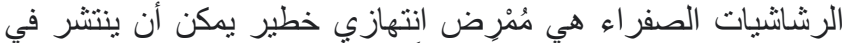

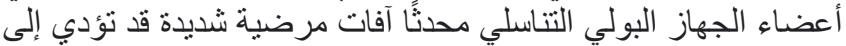

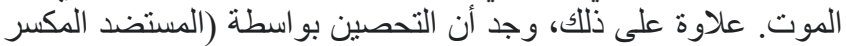
و السم الفطري المحور) يمكن أن يقلل بشكل كبير من التأثنير ات المناعية و المرضية للفطر وسمومه الفطرية الضارة. 